\title{
Situated embodied cognition: Monitoring orientation cues affects product evaluation and choice ${ }^{\dagger}$
}

\author{
Jiska Eelen $^{\text {a,* }}{ }^{\text {, Siegfried Dewitte }}{ }^{\text {a }}$, Luk Warlop ${ }^{\text {a, b }}$ \\ ${ }^{\text {a }}$ KU Leuven, Faculty of Business and Economics, Naamsestraat 69, B-3000 Leuven, Belgium \\ ${ }^{\mathrm{b}}$ BI Norwegian Business School, Nydalsveien 37, N-0484 Oslo, Norway
}

Received 7 April 2011; received in revised form 17 April 2013; accepted 18 April 2013

\begin{abstract}
Consumers generally prefer products that are easy to interact with. In three studies, we show that this preference arises from the fit between product orientation and monitored situational constraints. Flexible right-handers, who monitor situational constraints, recall product orientations better and prefer products for which the handle is oriented in the direction of the hand used for grasping. When their ability to monitor situational constraints is impaired, the preference for easy-to-grasp products is attenuated. The findings highlight that motor fluency is a relevant cue for decision making when consumers assess how to interact with a product. The implications of these results for embodiment and fluency research are discussed.
\end{abstract}

(C) 2013 Society for Consumer Psychology. Published by Elsevier Inc. All rights reserved.

Keywords: Embodiment; Situated cognition; Handedness; Processing fluency; Product orientation; Grasping

\section{Introduction}

Have you ever noticed that most bottled detergents on supermarket shelves are oriented with their handle towards the right of the brand label? Approximately $90 \%$ of the world's population is right-handed (Perelle \& Ehrman, 1994) which appears to have resulted in a product universe designed by and

\footnotetext{
it This manuscript is based on the dissertation of the first author under the supervision of the second and third author. The first author was funded by a $\mathrm{PhD}$ fellowship of the Research Foundation Flanders (FWO). The researchers thank Mike Friedman, Tom Meyvis, Paula Niedenthal, Klaus Wertenbroch, the dissertation committee, the participants of the EMAC doctoral colloquium (2010), AMA Sheth Consortium (2011), ACR (2010) and SCP conference (2010), the consumer behavior group at the KU Leuven, the ASCoR persuasive communication group at the University of Amsterdam, and the editors, as well as three anonymous reviewers for their valuable comments and suggestions.

* Corresponding author at: University of Amsterdam, Amsterdam School of Communication Research, Kloveniersburgwal 48, 1012 CX Amsterdam, The Netherlands.

E-mail addresses: J.Eelen@uva.nl (J. Eelen), Siegfried.Dewitte@kuleuven.be (S. Dewitte),Luk.Warlop@kuleuven.be (L. Warlop).
}

created for right-handers. Interestingly, the orientation of product handles impacts product evaluation (Elder \& Krishna, 2012; Ping, Dhillon, \& Beilock, 2009). For example, right-handers might prefer a detergent with the handle oriented rightwards rather than leftwards. This phenomenon is referred to as the motor fluency effect to emphasize that physical action can impact judgments (Ping et al., 2009). The finding is consistent with theories of embodied cognition, which posit that thinking relies on bodily experiences, such as perceptions, emotions and actions (Barsalou, 1999; Niedenthal, Barsalou, Winkielman, KrauthGruber, \& Ric, 2005). However, while the motor fluency effect has been demonstrated, the underlying process remains to be fully uncovered.

It has been suggested that we automatically activate previous experiences with a product when observing it (Elder \& Krishna, 2012). Therefore, a product oriented rightwards might fit best with right-handers' past product interactions and may appear more attractive than a product oriented leftwards. However, it is also possible that the orientation of a handle provides a cue for interaction within a given situation. In the latter case, even right-handers may prefer products oriented leftwards when 
left-handed product interaction is facilitated by the context. Theories of embodied cognition not only indicate that bodily experiences lie at the basis of thinking but also highlight that thinking is contextual and occurs in interaction with the environment (Barsalou, 2008; Niedenthal, Winkielman, Mondillon, \& Vermeulen, 2009). We therefore aim to disentangle possible mechanisms that explain why right-handers prefer products with the handle oriented rightwards. In case of the detergent, would right-handers prefer the bottle oriented rightwards because they have always grasped the bottle of detergent with the right hand in the past or because it appears easiest to grasp the product with the right hand at the time of observation? The contextual nature of the motor fluency effect has received no attention in past research.

In contrast with previous literature (Elder \& Krishna, 2012; Ping et al., 2009), we suggest that orientation cues do not automatically influence judgment. However, these cues influence judgment when consumers monitor how to interact with a product within a given situation. In three studies, we show that individual and situational differences in monitoring contextual cues of product interaction moderate the occurrence of the motor fluency effect. Flexible right-handers plan grasping actions more carefully than rigid right-handers. These individuals pay more attention to the orientation of handles, and are more strongly influenced by product orientation than rigid right-handers, unless monitoring situational constraints is hindered by taxing working memory. The primary contribution of the current work is to demonstrate that the context of decision making plays an important role in shaping the impact of orientation cues on product evaluation.

\section{Motor fluency}

Theories of embodied cognition indicate that knowledge is represented in memory by means of bodily experiences (Barsalou, 1999, 2008; Glenberg, 1997; Niedenthal, Eelen, \& Maringer, 2011). Consider the case of washing detergent. Its mental representation could consist of perceptions (e.g., the green color of the bottle or its odor), actions (e.g., grasping the bottle or opening it), and introspections (e.g., the feeling of putting on freshly washed clothes). If actions are part of how knowledge is represented, then action cues at the moment of information processing can facilitate or inhibit decision making (Dijkstra, Kaschak, \& Zwaan, 2007; Niedenthal, Brauer, Halberstadt, \& Innes-Ker, 2001). For example, understanding a sentence such as "Close the drawer" is easier while performing an action away from than towards oneself (Glenberg \& Kaschak, 2002). Moreover, the fluent processing of stimuli leads to more positive evaluations of those stimuli (for a review, see Alter \& Oppenheimer, 2009; Schwarz, 2004). Hence, it may not come as a surprise that easily performed actions give rise to positive feelings that spill over to the object of consideration. This phenomenon can be referred to as embodied cognitive fluency (Alter \& Oppenheimer, 2009) or motor fluency (Ping et al., 2009), because the feeling of ease results from bodily feedback, or more particularly motor behavior. Beilock and Holt (2007) were the first to show this effect. The authors demonstrated that expert typists preferred letter combinations that were easy to type, whereas novices did not show such preference.
An increasing amount of research has demonstrated the motor fluency effect in consumer behavior. Consumers appear to prefer products that are easy to grasp. For example, when given the choice between two dissimilar products (e.g., a bottle opener and ice cream scoop) with conflicting handle orientations left- and rightwards, right-handers were most likely to pick up and choose the product with the handle oriented rightwards (Ping et al., 2009). These findings have been replicated in a shopping context where participants were given the choice between two similar products (e.g., two pizza cutters from different brands) (Eelen, 2011). Furthermore, motor fluency effects have been observed to operate in the absence of physical motor behavior. Advertisements that visualize product usage with one's dominant hand (e.g., a bowl of yogurt that contains a spoon with the handle oriented rightwards for right-handers) instill higher purchase intentions than visualizations of usage with the non-dominant hand (Elder \& Krishna, 2012). Lastly, Shen and Sengupta (2012) showed that holding an object in one's dominant hand while observing a product decreases the liking of the observed product unless the held object facilitated grasping the observed product (e.g., a fork facilitates eating noodles).

To date, research has focused on demonstrating the occurrence of the motor fluency effect. However, it remains unclear when action cues, such as product orientation, are most likely to impact product evaluation. We believe that two mechanisms may explain the phenomenon of motor fluency. One mechanism may be that individuals automatically simulate previous product experiences when they observe a product. In that case right-handers may prefer objects oriented rightwards because they have always grasped objects with the right hand in the past. The match or mismatch between habitual grasping and the observed orientation then determines product attractiveness. This mechanism is largely driven by bodily constraints and was implicitly suggested by Ping et al. (2009) and Elder and Krishna (2012). Another mechanism may be that the ease of grasping is derived from actively monitoring the interaction between the body and constraints in the environment. What is mentally simulated may depend largely on the context. Hence, right-handers may even prefer products oriented leftwards when left-handed product interaction is facilitated by the context. The mechanism also implies that product orientation may only be a relevant cue for decision making when consumers assess how to act on an object. Embodiment theories favor the latter explanation, but an empirical test is needed.

\section{Automatic versus contextual impact of orientation cues on product evaluation}

Embodiment theories make precise claims regarding when and why sensorimotor information is simulated (Barsalou, 1999, 2008). Representations are only embodied to the extent that such information is needed to improve the understanding of the concept (Niedenthal, Mermillod, Maringer, \& Hess, 2010). For example, observing the word "HAPPINESS" triggers the simulation of a smile for individuals who judge its emotional value but not for those who judge the letter case the word is written in (Niedenthal et al., 2009). Similarly, we argue that observing a product may trigger action simulation more for individuals who rely on 


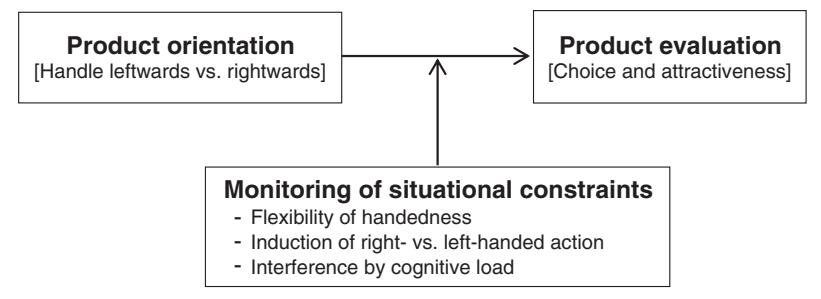

Fig. 1. Conceptual framework.

opportunities in the environment and plan interactions carefully than for those who rely on internal signals and act in habitual ways (Jeannerod, 1995). This assumption would imply that product orientation cues affect product evaluation only for individuals who consider situational constraints when interacting with products.

This reasoning is in line with the perspective of situated or grounded cognition (Barsalou, 2010; Robbins \& Aydede, 2008; Wilson, 2002). The framework highlights that "thinking is for doing" within a given context. Schwarz $(2006, \mathrm{p} 20)$ noted that "to serve action, people's cognition needs to be responsive to their goals and to the immediate social and physical environment in which they pursue them." For example, the color green might be activated when thinking of "watermelon" but the color red might be activated when thinking of "half watermelon" (Wu \& Barsalou, 2009). Similarly, individuals are likely to enact a vertical visual representation of a pencil when thinking of "a cup filled with pencils" but a horizontal representation of a pencil when they think of "pencils placed in a drawer" (Barsalou, 1999; Stanfield \& Zwaan, 2001). In the context of product interaction, Gibson (1979) introduced the concept of affordance, the idea that action possibilities of objects should be seen in relation to the actor. If not only bodily states but also the environment is incorporated in consumers' decision making, then the motor fluency effect may occur as a result of screening orientation cues to find a match between one's body characteristics and what a product affords at the time of observation. We argue that it would be functional to include the orientation of a product into its evaluation when individuals care about how to interact with the observed product. The orientation of product handles could inform consumers of the different opportunities for product interaction. Product representations may contain action information if such information is useful for decision making. Thus, rather than having an automatic impact on product evaluation, product orientation may be most likely to impact product evaluation when individuals monitor cues in the environment to plan actions.

\section{Overview of studies}

In three studies, we empirically test whether the impact of product orientation on product evaluation should be considered in light of the perspective of situated cognition. In our conceptual model (visually depicted in Fig. 1), orientation cues are screened in relation to situational constraints. Monitoring product orientation may be important to plan actions in accordance with what the environment affords. Therefore, the product that is easiest to interact with in the given situation may be preferred over others. Thus, we expect the extent to which individuals monitor situational constraints to moderate the influence of product orientation on product evaluation and choice.

We operationalize the monitoring of situational constraints in three different ways. We first examine the individual difference in the flexibility of handedness (Annett, 1976; Oldfield, 1971). Flexible right-handers have a preference for using the right hand in product interaction, but occasionally switch to the left hand, for example when an object lies to the left of them (Bryden, Pryde, \& Roy, 2000; Gonzalez \& Goodale, 2009; Gonzalez, Whitwell, Morrissey, Ganel, \& Goodale, 2007). This observation implies that monitoring situational constraints is more important for flexible right-handers than for rigid right-handers. We test this assumption in the first study and build upon it in the subsequent studies. Second, we underscore the importance of situational constraints by inducing left- and right-handed action. Third, we induce cognitive load in working memory to prevent monitoring of situational constraints. In summary, we explore in three behavioral experiments how these individual and situational differences in the importance of action planning influence the use of orientation cues in product evaluation.

\section{Study 1}

This study tests the proposition that flexible right-handers pay more attention to orientation cues than do rigid right-handers. This proposition would allow for us to use individual differences as a proxy for monitoring situational constraints in follow-up studies. Whereas a large majority of individuals prefers to use the right hand for manipulating objects, not all right-handers are exclusively right-handed (Annett, 1972). Rigid right-handers are less flexible in switching hands while interacting with their environment and manipulate objects with the dominant right hand, while more flexible right-handers are sensitive to situational constraints when choosing which hand to use (Bryden et al., 2000; Gonzalez \& Goodale, 2009). Flexibly adapting an action plan requires more encoding of context, constraints and environmental perturbations than performing an internalized action plan (Jeannerod, 1995). We predict that, after being exposed to different products with handles, flexible right-handers will recall the orientation of product handles better than rigid right-handers. The degree of handedness can be measured using performance measures (e.g., peg moving, Annett, 1976; (precision) grasping, Bryden et al., 2000; grip strength, Gonzalez \& Goodale, 2009) or hand preference questionnaires (e.g., Oldfield, 1971). For righthanders, different measures are highly correlated (Brown, Roy, Rohr, \& Bryden, 2006). Here, the degree of handedness is measured using a hand preference questionnaire for the products presented in the study.

\section{Method}

\section{Participants}

In return for monetary compensation 60 university students (26 males) were recruited from a subject pool to participate in the present study and several other unrelated studies. All participants were between 19 and 32 years of age $(M=21.93, S D=2.04)$ and were prescreened to be right-handers (i.e., determined based 
on the hand with which the individual writes, Perelle \& Ehrman, 2009).

\section{Procedure}

The participants viewed a presentation of 24 products (see Appendix) on a computer screen, expecting questions regarding the products afterwards. Twelve target products had a handle oriented rightwards (i.e., six products with an angle of $135^{\circ}$ ) or leftwards (i.e., six products with an angle of $-135^{\circ}$ ) and 12 filler products had no handle. The presentation of target and filler products was randomized, with the restriction that target and filler trials were alternated and no more than three subsequent target trials had a similar handle orientation. The handle orientation of products was randomized across participants. Subsequently, the participants performed a cued recall task in which they were asked to reproduce the orientation of the handle of the target products (i.e., a binary choice, leftwards or rightwards) and to indicate confidence about each answer on a 6-point scale (from $50 \%=$ not confident at all, just guessing to $100 \%=$ absolutely confident, with $10 \%$ intervals). Lastly, the participants reported on a 5-point scale $(1=$ always with my left hand and $5=$ always with my right hand) which hand they would use for manipulating the 12 target products presented in the first phase.

\section{Results and discussion}

To create an overall performance measure for each participant, orientation answers of all 12 target products were coded for correctness (i.e., 0 is incorrect, 1 is correct), multiplied by their level of confidence and aggregated. The degree of handedness resulted from aggregating the handedness scores of the target products (Cronbach's $\alpha=.81$ ). In all of the studies, the participants scored between 3 (i.e., ambidextrous) and 5 (i.e., exclusively right-handed) on the degree of handedness, indicating that all right-handers indeed showed a preference for manipulating objects with the right hand. Two of the participants indicated in the debriefing that they had explicitly attempted to memorize the handle orientations. These observations were excluded from further analyses but did not affect the statistical results. We observed a significant negative correlation between participants' degree of handedness and performance $(r=-.34, p=.01$; without correction for confidence: $r=-.26$, $p=.05)$. Both the left $(r=-.29, p=.03)$ and the right orientations of handles $(r=-.28, p=.04)$ accounted for this result. This result indicates that flexible right-handers perform better on the task and hence appear to pay more attention to orientation cues in their environment than rigid right-handers. Although reversed causality (i.e., better performance leads to more flexible right-handedness) appears less likely to explain these findings, the degree of handedness in Study 2 is measured using items that are not part of the actual study.

\section{Study 2}

In Study 1 we demonstrated that flexible right-handers pay more attention to orientation cues. Here, we use this individual difference to determine whether monitoring situational constraints moderates the influence of product orientation on evaluation. In different trials, the participants are requested to indicate their product preference between pairs of products for which the handle orientation is manipulated. We expect that the product orientation has a larger impact on flexible than rigid right-handers. In addition, we induce situational constraints and test whether left- and right-handed actions have a different impact on product evaluation. We predict that flexible righthanders will rely on situational constraints and show a preference for products oriented rightwards when using the right hand, but a reversed preference for products oriented leftwards when using the left hand. Given that rigid right-handers do not rely on external cues to execute actions, we do not expect situational constraints to impact their product preferences.

\section{Method}

\section{Participants}

In return for monetary compensation, 67 university students (16 males) were recruited from a subject pool to participate in the present study and several other unrelated studies. All participants were between 18 and 24 years of age $(M=20.78, S D=1.49)$ and were prescreened to be right-handers (see Study 1).

\section{Procedure and materials}

The participants were shown pairs of similar products (i.e., utensils for cooking, hygiene, and other home purposes) on a computer screen. At each trial, the participants were asked to choose as rapidly as possible which product they preferred to use. The participants were randomly assigned to using the left hand or right hand for making choices. They indicated their answer by pressing the letter " $\mathrm{D}$ " on the computer keyboard if they preferred the product presented on the left side of the screen or pressing the "K" key if they chose the product on the right side. Pictures of products are not graspable, but previous research has shown that mental simulation of grasping also occurs in response to images of products, with right- (vs. left-) handed button interactions facilitating the processing of products with the handle oriented rightwards (vs. leftwards) (Tucker \& Ellis, 1998). In eight target trials, the handles of the two products pointed in opposite directions (i.e., products oriented rightwards in an angle of $100^{\circ}$ and products oriented leftwards in an angle of $-100^{\circ}$ ). In half of these trials, the product oriented rightwards was shown on the right side of the screen, whereas in the other half, the product oriented rightwards was shown on the left side (see A and B in Fig. 2). In four filler trials, the handles of the products were oriented in the same direction (twice leftwards and twice rightwards; see Fig. $2 \mathrm{C}$ and $\mathrm{D}$ ) and four other filler trials consisted of product pairs without handles. We randomized the order of trials within participants, in addition to randomizing which item of product pairs was presented on the left or right side of the screen. All of the product pairs with handles were randomly selected to be target or filler trials. After the choice task, the participants were asked to write down their thoughts when deciding which products to choose, and to guess what the study was about. 


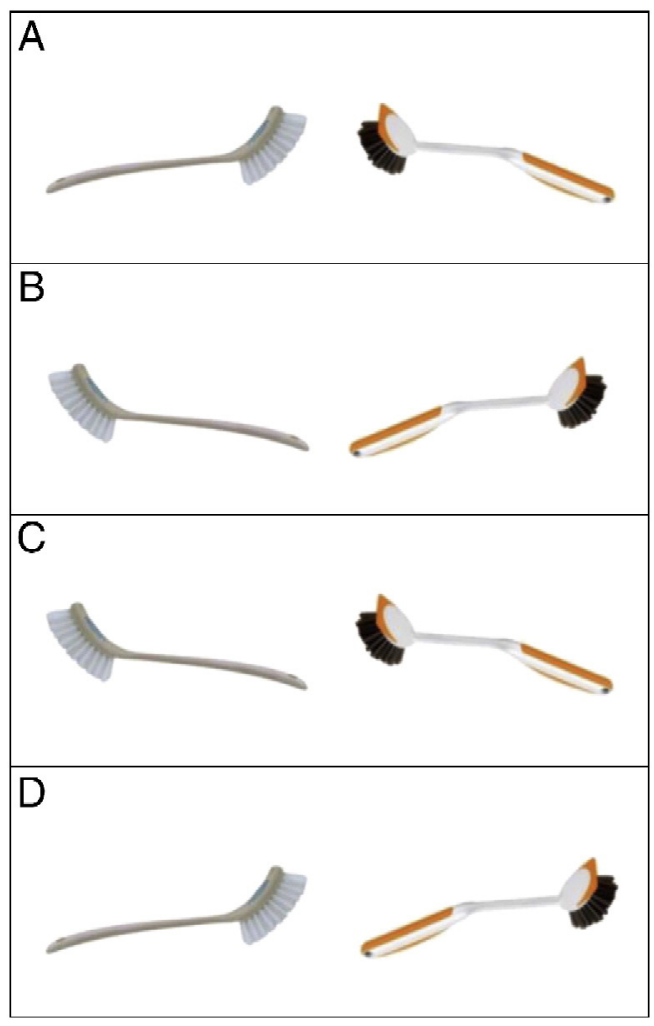

Fig. 2. Four possible presentation configurations of the products in Study 2. A and $\mathrm{B}$ represent target trials in which a conflict in grasping orientation is induced, whereas $\mathrm{C}$ and $\mathrm{D}$ are filler trials.

\section{Degree of handedness}

Among other unrelated studies following the choice task, the participants completed the handedness scale (for a discussion of this measure, see Curt, Mesbah, Lellouch, \& Dellatolas, 1997) in which they reported on a 5-point scale $(1=$ always with my left hand and $5=$ always with my right hand) which hand they would use for manipulating 12 different objects (e.g., use a spoon, tennis racket).

\section{Results and discussion}

Two participants (i.e., one in each hand condition) correctly guessed the purpose of the study and were excluded from further analyses. The removal of these participants did not affect the statistical results. For each participant we created a percentage score indicating how often products oriented rightwards were chosen in the eight target trials. We conducted a general linear model (GLM) analysis on the percentage scores with hand used (left vs. right) and degree of handedness as independent between-subjects variables.

A main effect of hand use emerged, $F(1,61)=13.10, p=$ .0006 , indicating that, on average, the participants who used the right hand chose products oriented rightwards more frequently $(53 \%, S E=2 \%)$ than participants using the left hand $(43 \%$, $S E=3 \%)$. There was no main effect of the degree of handedness, $F<1$. Most important was the significant interaction effect of the hand used and the degree of handedness, $F(1,61)=12.10, p=$ .0009 (see Fig. 3).

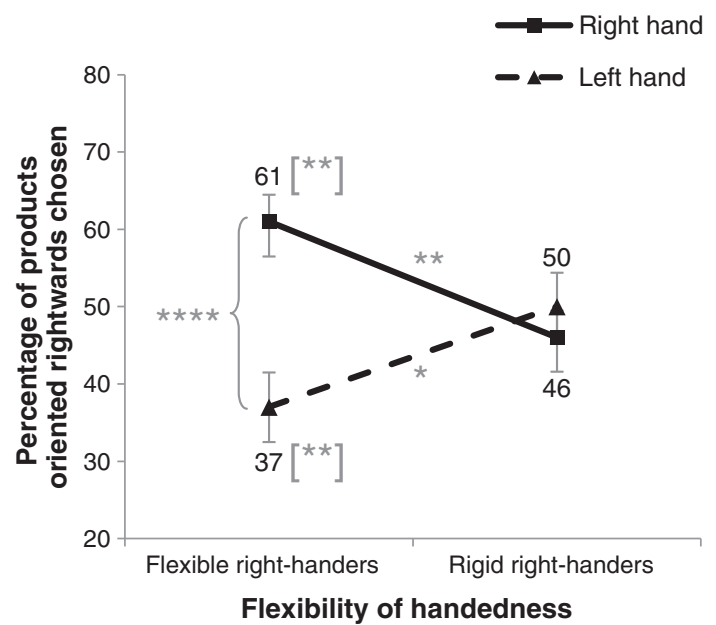

Fig. 3. The percentage of products with a handle oriented rightwards chosen, as a function of the degree of handedness and the hand used to make choices in Study 2 . The significances between brackets indicate to what extent the values differ from a random choice pattern (i.e., 50\%). Error bars represent standard errors. ${ }^{*} p<.05 .{ }^{* *} p<.01 .{ }^{* * *} p<.001 .{ }^{* * * *} p<.0001$.

Simple effects analyses demonstrate that product evaluations of flexible right-handers were affected by situational constraints, whereas those of rigid right-handers were not. Flexible righthanders $(M-1 S D)$ who used the right hand for making choices had a preference for products oriented rightwards $(61 \%, S E=$ $3 \%, t(64)=3.15, p=.003)$, whereas flexible right-handers who used the left hand had the opposite preference $(37 \%, S E=5 \%$, $t(64)=-2.94, p=.005)$. Rigid right-handers $(M+1 S D)$ did not exhibit a preference for products oriented rightwards (or leftwards), neither with the right hand $(46 \%, S E=3 \%$, $t(64)=-1.16, p=.25)$ nor with the left hand $(50 \%, S E=4 \%$, $t(64)=.03, p=.97)$. Simple slope analyses indicate that more flexible right-handers showed stronger motor fluency effects than rigid right-handers, both with the left hand $(\beta=-24$, $t(64)=-2.06, p=.04)$ and the right hand $(\beta=27, t(64)=$ $3.03, p=.004)$.

This pattern of findings indicates that the monitoring of situational constraints moderates the impact of product orientation on evaluation. Flexible right-handers were affected by product orientation because they prepare actions by monitoring situational constraints and match these cues with what the body permits at the time of decision making. Therefore, facilitating right-handed actions instilled a preference for products oriented rightwards, and vice versa for left-handed actions. Rigid right-handers who do not rely on external cues for action planning were unaffected by product orientation. These findings suggest that individuals do not merely automatically reactivate previous product experiences. If that had been the case, we would have observed that right-handers always prefer products oriented rightwards and that the effect would have been strongest for rigid right-handers.

\section{Study 3}

In Study 2, we determined that product orientation affects evaluation for individuals who plan product interactions and 
monitor situational constraints of action. We therefore test whether the inhibition of monitoring situational constraints attenuates the impact of product orientation on evaluation. In contrast with the previous study, participants are not requested to perform any movement while looking at products. Hence, we expect that flexible right-handers who have the opportunity to monitor situational constraints prefer products that are oriented rightwards (i.e., the most fluent interaction with the preferred right hand). However, we expect that cognitive load in working memory, or distraction, will eliminate the opportunity to monitor situational constraints and will therefore reduce motor fluency effects for flexible right-handers. Our prediction is based on the suggestion that it is cognitively effortful to consider situational constraints when planning actions (Jeannerod, 1995; Norman \& Shallice, 1986). This assumption has been demonstrated by the undermined performance of working memory on parallel spatial and verbal tasks (Spiegel, Koester, Weigelt, \& Schack, 2012; Weigelt, Rosenbaum, Huelshorst, \& Schack, 2009). As in Studies 1 and 2, we predict no effects of product orientation on rigid right-handers.

\section{Method}

\section{Participants}

In return for partial course credit, 106 university students (64 males) were recruited. All participants were between 18 and 23 years of age $(M=19.25, S D=1.30)$ and were prescreened to be right-handers (see Study 1).

\section{Procedure and materials}

The instructions were presented on a computer screen. The participants were informed that they were about to see the image of a product as it would be used in an advertising campaign and were going to answer questions about the products afterwards. We then informed the participants that they would have to memorize a number while observing the product to simulate a distracting real-life situation in which individuals encounter advertisements (Shiv \& Fedorikhin, 1999). In the "low distraction" condition, the participants were requested to memorize the 2-digit number ' 75 '. The other half of the participants, in the "high distraction" condition, was requested to memorize the 9-digit number '753293142'. Next, the advertisement task began in which a designer water boiler was shown for $5 \mathrm{~s}$. Half of all the participants were shown the water boiler with its handle oriented rightwards. The other half saw the boiler with its handle oriented leftwards. Following this presentation, the participants had to indicate how attractive they considered the water boiler on a visual analog scale ranging from not attractive at all to very attractive (200 points). Subsequently, the participants were requested to report the number they had memorized. Lastly, to assess the degree of handedness, after several filler tasks, the participants indicated which hand they would use for manipulating a water boiler on a 5-point scale (ranging from $1=$ always with my left hand to $5=$ always with my right hand).

\section{Results and discussion}

Six participants (all from the high distraction condition) were unable to recall the correct number at the end of the study and were discarded from further analysis. Distraction (low vs. high) and product orientation (left vs. right) were entered as discrete between-subject variables in a GLM analysis, and the degree of handedness was entered as a continuous between-subject variable. Flexible right-handers gave marginally significantly higher ratings of attractiveness than did rigid right-handers, $\beta=$ -7.40, $F(1,92)=3.67, p=.06$. The two-way interactions 'Product orientation $\times$ Distraction', $F(1,92)=4.94, p=.03$, and 'Degree of handedness $\times$ Distraction', $F(1,92)=7.28, p=.008$, were significant. However, all of these findings were qualified by a significant three-way-interaction among product orientation, distraction and degree of handedness, $F(1,92)=5.79, p=.02$ (see Fig. 4). No other effects were significant, $p$ s $>.18$. To further interpret the three-way-interaction in detail, the GLM analyses were split for the distracted and undistracted condition. All of the simple slopes and simple effects analyses are conducted within the overall GLM analysis.

We first examined the undistracted condition. When performing a GLM analysis with product orientation and degree of handedness within the undistracted condition, we observed a main effect of degree of handedness, $F(1,48)=11.97, p=$ .001 . More flexible right-handers gave higher ratings than rigid right-handers, $\beta=-29.24, t(51)=-3.46$. There was no main effect of handle orientation, $F<1$. Importantly, we observed the expected two-way-interaction between degree of handedness and product orientation, $F(1,48)=4.26, p=.04$. Simple slope and effects analyses help explain the pattern of the findings. Flexible right-handers found the boiler oriented rightwards more attractive than did rigid right-handers, $\beta=-28.47, t(99)=$ $-3.21, p=.002$. Flexible and rigid right-handers did not differ in attractiveness ratings for the boiler oriented leftwards, $\beta=-7.19, t(99)=-1.09, p=.28$. Flexible right-handers $(M-1 S D)$ tended to find the boiler oriented rightwards more attractive $(M=132.32, S E=9.24)$ than the boiler oriented leftwards $(M=111.47, S E=7.59, \quad t(99)=1.74, \quad p=.08)$. Rigid right-handers $(M+1 S D)$ found the boiler oriented rightwards $(M=85.63, S E=10.29)$ and leftwards $(M=99.67$, $S E=7.92)$ equally attractive, $t(99)=-1.08, p=.28$. Hence, Study 2 is replicated showing a motor fluency effect for flexible but not for rigid right-handers. The findings indicate that flexible right-handers have a natural preference for products oriented rightwards.

We then examined the pattern of findings in the distracted condition. In line with our expectations, a GLM analysis with product orientation and degree of handedness within the distracted condition did not show any significant main or interaction effects, $p \mathrm{~s}>.17$. Flexible and rigid right-handers did not differ in attractiveness ratings for the boiler oriented leftwards, $\beta=-4.93, t(99)=-.62, p=.54$, or rightwards, $\beta=10.98$, $t(99)=1.50, p=.14$.

Lastly, a planned contrast shows that distracted flexible right-handers tended to judge the boiler oriented rightwards as less attractive $(M=107.79, S E=9.34)$ than did undistracted 


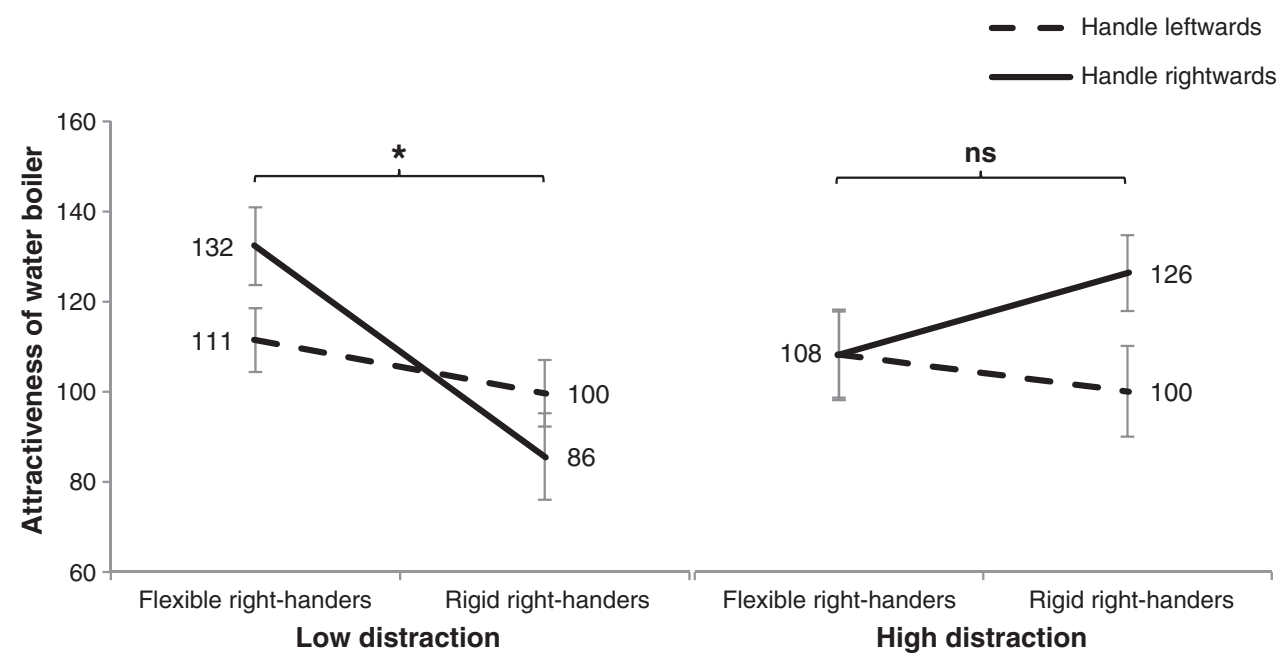

Fig. 4. Attractiveness of a water boiler as a function of distraction, product orientation and the degree of handedness in Study 3. The error bars represent standard errors. ${ }^{*} p<.05$

flexible right-handers $(M=132.32, S E=9.24, t(99)=-1.87$, $p=.07)$. Taken together, we find evidence that the inhibition of monitoring situational constraints attenuates the impact of product orientation on evaluation for flexible right-handers.

For the sake of completeness we mention the two significant post-hoc contrasts for rigid right-handers. It was observed that distracted rigid right-handers rated the boiler oriented rightwards as more attractive $(M=125.80, S E=7.82)$ than the boiler oriented leftwards $(M=99.76, S E=9.35, t(99)=2.14$, $p=.04)$. Distracted rigid right-handers found the boiler oriented rightwards more attractive $(M=125.80, S E=7.82)$ than did undistracted rigid right-handers $(M=85.63, S E=10.29), t(99)=$ $3.11, p=.003$. It appears that distraction increased the preference of the boiler rightwards for rigid right-handers. This unexpected finding is discussed in the general discussion.

\section{General discussion}

Products that are easy to interact with are liked better by consumers (Eelen, 2011; Elder \& Krishna, 2012; Ping et al., 2009; Shen \& Sengupta, 2012). In this research we examined the contextual nature of this motor fluency effect. We sought to determine if ease of interaction relies merely on bodily constraints or on the interplay between the body and the situation in which decision making occurs. If only bodily constraints impact decision making, then right-handers would never prefer products oriented leftwards. Moreover, right-handers who strongly prefer using the right hand would show stronger motor fluency effects than right-handers who are more flexible in switching to the left hand. However, our research shows that paying attention to situational constraints is an important boundary condition for the influence of product orientation (i.e., handle leftwards or rightwards) on product evaluation and choice for right-handers. We demonstrated that individual and situational differences in monitoring contextual constraints of product interaction moderate the motor fluency effect.
We found that flexible right-handers showed stronger motor fluency effects than rigid right-handers (Study 2 and 3), because they pay more attention to orientation cues than do rigid right-handers (Study 1). Moreover, the direction of the effect depended heavily on situational factors (Study 2). Inducing right- (vs. left-) handed actions increased the liking of products oriented right- (vs. leftwards). Lastly, cognitive load limited monitoring situational constraints and reduced the influence of product orientation on evaluation for flexible right-handers (Study 3). Together, the studies suggest that motor fluency is an evaluative response that arises when individuals who monitor situational constraints experience fewer situational constraints.

The current findings suggest that certain consumers engage in more extensive mental preparation of action when observing products than others. The findings are consistent with research on action planning. Changing action plans requires more attention to situational factors than performing habitual action plans (Jeannerod, 1995). Hence, individuals who rely more heavily on contextual factors are more liable to motor fluency effects. These findings are also consistent with the idea that mental simulations are only embodied to the extent that such information is needed to improve the understanding of the concept (Barsalou, 1999; Niedenthal et al., 2010). Furthermore, the results highlight that cognition does not occur in a vacuum but within a given context that can affect information processing, as stated by the perspective of situated cognition (Robbins \& Aydede, 2008; Schwarz, 2006; Smith \& Semin, 2007). One prediction that follows from our conceptual model is that the influence of motor fluency effects may be the largest for novel products for which consumers cannot rely on preexisting action plans. We also predict that motor fluency effects may be stronger when consumers' mindset focuses on product usage rather than, for example, on price. A slogan such as "Stir up some fresh ideas" on the cookware webpage of Ikea may therefore increase the impact of product orientation on evaluation. 
We believe that situational constraints were present in previous consumer research on the motor fluency effect, hence increasing the impact of product interactions on product evaluation. For example, in past studies, the participants were engaged in grasping products (Eelen, 2011; Ping et al., 2009), were shown pictures of actual product usage (Elder \& Krishna, 2012), or held another object while observing products (Elder \& Krishna, 2012; Shen \& Sengupta, 2012). The occurrence of the motor fluency effect in these studies is consistent with our argument that motor simulation may be essential particularly when individuals think about how to interact with a product within a given situation. Neuropsychological research could strengthen our understanding of when motor simulation is part of information processing, and when it is not.

Our findings are consistent with previous outcomes regarding motor fluency. Study 2 showed that right-handers who used the left hand for action preferred products oriented leftwards. Motor fluency effects have previously been found to be context-specific. Whereas right-handers generally associate the right side of action space with good things and the left side with bad things (Casasanto, 2009), those associations can be reversed when right-handers temporarily engage in tasks with the left hand (Casasanto \& Chrysikou, 2011). Study 3 replicated the finding that actual grasping movements are not a prerequisite to observe motor fluency effects (in agreement with Elder \& Krishna, 2012; Shen \& Sengupta, 2012). Therefore, these findings are also of interest to practitioners in diverse domains, such as advertising and online shopping.

Importantly, the current findings also contribute to fluency research more generally. In Study 3, we demonstrated that the effect was driven by the increased liking of products oriented rightwards, rather than by the decreased liking of products oriented leftwards. This finding reinforces and extends the literature that shows that processing fluency is affectively positive (Reber, Winkielman, \& Schwarz, 1998; Winkielman, Schwarz, Fazendeiro, \& Reber, 2003). Past fluency research has shown perceptual fluency effects (e.g., Reber et al., 1998) wherein repeated exposures to the exact same product enhanced the evaluation of the product, presumably by making perceptual features easier to identify. Conceptual fluency effects have also been shown (e.g., Lee \& Labroo, 2004), whereby exposure to related products made elaboration about the current product easier. Our work shows that easing situational constraints similarly evokes fluency experiences, at least for individuals with a high tendency to monitor such constraints. It may be interesting to reconsider previous fluency results in terms of perceptual and conceptual constraints on processing, and for whom such constraints are more likely to matter.

One unexpected finding in Study 3 calls for further research. Rigid right-handers appeared subject to a preference for objects oriented rightwards when placed under cognitive load. One speculative suggestion worth examining is that if undistracted rigid right-handers employ few mental resources to plan actions, they may pay more attention to other product characteristics (e.g., design, color or price). Rigid right-handers under cognitive load may then no longer have the capacity to attend to these characteristics and show an automatic preference for products that are easy to interact with. The finding in Study 3 could indicate that motor fluency may not only result from monitoring situational constraints but also from the automatic reactivation of previous product experiences. However, based on the overall pattern of findings there is more evidence for the former than the latter mechanism. It should be noted that we do not argue that rigid right-handers never simulate actions. We simply state that extensive motor simulation may be less essential to these individuals if habitual actions can be relied upon. Future research could investigate which decision cues rigid right-handers spontaneously rely on when undistracted. Focusing on product usage may also activate motor fluency for undistracted rigid right-handers.

Wide areas of research in cognitive and social psychology, consumer behavior and neuroscience now offer evidence that our body can influence higher order cognition in domains such as language (Glenberg, 1997) and emotion processing (Niedenthal et al., 2001, 2009), action understanding (Tucker \& Ellis, 1998), self-regulation (Hung \& Labroo, 2011) and trust (IJzerman \& Semin, 2009; Williams \& Bargh, 2008). The present work on product preferences is in line with theories of embodiment by showing that consumers' (simulated) physical interactions with products can impact decision making processes. Not only do our findings indicate that information processing is embodied, such that actions can impact preference construction, but we also go beyond this main effect of embodiment and demonstrate that it is flexible and situated. Product orientation affects product evaluation, but primarily does so for individuals who consider situational constraints when interacting with the world. Our research thus highlights the notion that embodiment is context-dependent (Niedenthal et al., 2010) and suggests that researchers should not only show that embodiment effects exist, but also understand when these effects occur.

\section{Appendix}

In Study 1, only one object was presented in each trial, whereas in Study 2 pairs of objects were presented. Products with handles were all used for target trials in Study 1, and used for target and filler trials in Study 2.

\section{Products with a handle}

Cleaning brush, flashlight, gardening fork, ice cream scoop, mug, pan, pasta fork, sieve, water boiler, water jug, whisk, and wrench.

\section{Products without a handle}

Used in both studies: bottle of wine, hairspray, pillow, and potato chips. Additional stimuli for Study 1: box of cereals, clock, box of dishwashing tablets, glass, hat, lamp, nailbrush, and vase. 


\section{References}

Alter, A. L., \& Oppenheimer, D. M. (2009). Uniting the tribes of fluency to form a metacognitive nation. Personality and Social Psychology Review, 13(3), 219-235. http://dx.doi.org/10.1177/1088868309341564.

Annett, M. (1972). The distribution of manual asymmetry. British Journal of Psychology, 63(3), 343-358.

Annett, M. (1976). A coordination of hand preference and skill replicated. British Journal of Psychology, 67(4), 587-592.

Barsalou, L. W. (1999). Perceptual symbol systems. The Behavioral and Brain Sciences, 22(4), 577-660. http://dx.doi.org/10.1017/s0140525x 99002149.

Barsalou, L. W. (2008). Grounded cognition. Annual Review of Psychology, 59(1), 617-645. http://dx.doi.org/10.1146/annurev.psych.59.103006.093639.

Barsalou, L. W. (2010). Grounded cognition: Past, present, and future. Topics in Cognitive Science, 2, 716-724. http://dx.doi.org/10.1111/j.1756-8765. 2010.01115.x.

Beilock, S. L., \& Holt, L. E. (2007). Embodied preference judgments: Can likeability be driven by the motor system? Psychological Science, 18(1), 51-57. http://dx.doi.org/10.1111/j.1467-9280.2007.01848.x.

Brown, S. G., Roy, E. A., Rohr, L. E., \& Bryden, P. J. (2006). Using hand performance measures to predict handedness. Laterality, 11(1), 1-14. http://dx.doi.org/10.1080/1357650054200000440.

Bryden, P. J., Pryde, K. M., \& Roy, E. A. (2000). A performance measure of the degree of hand preference. Brain and Cognition, 44, 402-414. http://dx.doi.org/10.1006/brcg.1999.1201.

Casasanto, D. (2009). Embodiment of abstract concepts: Good and bad in rightand left-handers. Journal of Experimental Psychology. General, 138(3), 351-367. http://dx.doi.org/10.1037/a0015854.

Casasanto, D., \& Chrysikou, E. G. (2011). When left is "right": Motor fluency shapes abstract concepts. Psychological Science, 22(4), 419-422. http://dx.doi.org/10.1177/0956797611401755.

Curt, F., Mesbah, M., Lellouch, J., \& Dellatolas, G. (1997). Handedness scale: How many and which items? Laterality, 2(2), 137-154. http://dx.doi.org/ 10.1080/713754262

Dijkstra, K., Kaschak, M. P., \& Zwaan, R. A. (2007). Body posture facilitates retrieval of autobiographical memories. Cognition, 102(1), 139-149. http://dx.doi.org/10.1016/j.cognition.2005.12.009.

Eelen, J. (2011). Situated consumer behavior: The impact of bodily influences on decision making. (Unpublished doctoral dissertation). University of Leuven.

Elder, R. S., \& Krishna, A. (2012). The "visual depiction effect" in advertising: Facilitating embodied mental simulation through product orientation. Journal of Consumer Research. http://dx.doi.org/10.1086/661531.

Gibson, J. J. (1979). The ecological approach to visual perception. Boston: Houghton, Mifflin and Company.

Glenberg, A. M. (1997). What memory is for. The Behavioral and Brain Sciences, 20(1), 1-55. http://dx.doi.org/10.1017/s0140525x97000010.

Glenberg, A. M., \& Kaschak, M. P. (2002). Grounding language in action. Psychonomic Bulletin \& Review, 9(3), 558-565. http://dx.doi.org/ 10.3758/BF03196313.

Gonzalez, C. L. R., \& Goodale, M. A. (2009). Hand preference for precision grasping predicts language lateralization. Neuropsychologia, 47, 3182-3189. http://dx.doi.org/10.1016/j.neuropsychologia.2009.07. 019

Gonzalez, C. L. R., Whitwell, R. L., Morrissey, B., Ganel, T., \& Goodale, M. A. (2007). Left handedness does not extend to visually guided precision grasping. Experimental Brain Research, 182(2), 275. http://dx.doi.org/ 10.1007/s00221-007-1090-1.

Hung, I. W., \& Labroo, A. A. (2011). From firm muscles to firm willpower: Understanding the role of embodied cognition in self-regulation. Journal of Consumer Research, 37(3), 1046-1064. http://dx.doi.org/10.1086/ 657240

IJzerman, H., \& Semin, G. R. (2009). The thermometer of social relationships: Mapping social proximity on temperature. Psychological Science, 20(10), $1214-1220$

Jeannerod, M. (1995). Mental imagery in the motor context. Neuropsychologia, 33(11), 1419-1432. http://dx.doi.org/10.1016/0028-3932(95)00073-C.
Lee, A. Y., \& Labroo, A. A. (2004). The effect of conceptual and perceptual fluency on brand evaluation. Journal of Marketing Research, 41(2), 151-165. http://dx.doi.org/10.1509/jmkr.41.2.151.28665.

Niedenthal, P. M., Barsalou, L. W., Winkielman, P., Krauth-Gruber, S., \& Ric, F. (2005). Embodiment in attitudes, social perception, and emotion. Personality and Social Psychology Review, 9(3), 184-211. http://dx.doi.org/ 10.1207/s15327957pspr0903_1.

Niedenthal, P. M., Brauer, M., Halberstadt, J. B., \& Innes-Ker, A. H. (2001). When did her smile drop? Facial mimicry and the influences of emotional state on the detection of change in emotional expression. Cognition \& Emotion, 15(6), 853-864.

Niedenthal, P. M., Eelen, J., \& Maringer, M. (2011). Embodiment and social cognition. In J. Decety, \& J. T. Cacioppo (Eds.), The Oxford handbook of social neuroscience (pp. 491-506). New York: Oxford University Press.

Niedenthal, P. M., Mermillod, M., Maringer, M., \& Hess, U. (2010). The simulation of smiles (SIMS) model: Embodied simulation and the meaning of facial expression. The Behavioral and Brain Sciences, 33(6), 417-433. http://dx.doi.org/10.1017/S0140525X10000865.

Niedenthal, P. M., Winkielman, P., Mondillon, L., \& Vermeulen, N. (2009). Embodiment of emotion concepts. Journal of Personality and Social Psychology, 96(6), 1120-1136. http://dx.doi.org/10.1037/a0015574.

Norman, D. A., \& Shallice, T. (1986). Attention to action: Willed and automatic control of behavior. In R. J. Davidson, G. E. Schwartz, \& D. Shapiro (Eds.), Consciousness and self-regulation: Advances in research (Vol. 4, pp. 118). New York: Plenum Press.

Oldfield, R. C. (1971). The assessment and analysis of handedness: The Edinburgh inventory. Neuropsychologia, 9, 97-113. http://dx.doi.org/10.1016/ 0028-3932(71)90067-4.

Perelle, I. B., \& Ehrman, L. (1994). An international study of human handedness: The data. Behavior Genetics, 24(3), 217-227. http://dx.doi.org/ $10.1007 / \mathrm{bf0} 01067189$

Perelle, I. B., \& Ehrman, L. (2009). Handedness: A behavioral laterality manifestation. In K. Yong-Kyu (Ed.), Handbook of behavior genetics (pp. 331-342). New York: Springer. http://dx.doi.org/10.1007/978-0-38776727-7_23

Ping, R. M., Dhillon, S., \& Beilock, S. L. (2009). Reach for what you like: The body's role in shaping preferences. Emotion Review, 1(2), 140-150. http://dx.doi.org/10.1177/1754073908100439.

Reber, R., Winkielman, P., \& Schwarz, N. (1998). Effects of perceptual fluency on affective judgments. Psychological Science, 9(1), 45-48. http: //dx.doi.org/10.1111/1467-9280.00008.

Robbins, P., \& Aydede, M. (2008). A short primer on situated cognition. In P. Robbins, \& M. Aydede (Eds.), Cambridge handbook of situated cognition (pp. 3-10). Cambridge: Cambridge University Press.

Schwarz, N. (2004). Metacognitive experiences in consumer judgment and decision making. Journal of Consumer Psychology, 14(4), 332-348. http://dx.doi.org/10.1207/s15327663jcp1404_2.

Schwarz, N. (2006). Feelings, fit, and funny effects: A situated cognition perspective. Journal of Marketing Research, 43(1), 20-23. http://dx.doi.org/ 10.1509/jmkr.43.1.20

Shen, H., \& Sengupta, J. (2012). If you can't grab it, it won't grab you: The effect of restricting the dominant hand on target evaluations. Journal of Experimental Social Psychology. http://dx.doi.org/10.1016/j.jesp.2011.11.003.

Shiv, B., \& Fedorikhin, A. (1999). Heart and mind in conflict: The interplay of affect and cognition in consumer decision making. Journal of Consumer Research, 26(3), 278-292. http://dx.doi.org/10.1086/209563.

Smith, E. R., \& Semin, G. R. (2007). Situated social cognition. Current Directions in Psychological Science, 16(3), 132-135. http://dx.doi.org/ 10.1111/j.1467-8721.2007.00490.x.

Spiegel, M. A., Koester, D., Weigelt, M., \& Schack, T. (2012). The costs of changing an intended action: Movement planning, but not execution, interferes with verbal working memory. Neuroscience Letters, 509(2), 82-86. http://dx.doi.org/10.1016/j.neulet.2011.12.033.

Stanfield, R. A., \& Zwaan, R. A. (2001). The effect of implied orientation derived from verbal context on picture recognition. Psychological Science, 12(2), 153-156. http://dx.doi.org/10.1111/1467-9280.00326.

Tucker, M., \& Ellis, R. (1998). On the relations between seen objects and components of potential actions. Journal of Experimental Psychology. Human 
Perception and Performance, 24(3), 830-846. http://dx.doi.org/10.1037/ 0096-1523.24.3.830.

Weigelt, M., Rosenbaum, D. A., Huelshorst, S., \& Schack, T. (2009). Moving and memorizing: Motor planning modulates the recency effect in serial and free recall. Acta Psychologica, 132(1), 68-79. http://dx.doi.org/10.1016/ j.actpsy.2009.06.005.

Williams, L. E., \& Bargh, J. A. (2008). Experiencing physical warmth promotes interpersonal warmth. Science, 322(5901), 606-607. http://dx.doi.org/ 10.1126/science. 1162548 .
Wilson, M. (2002). Six views of embodied cognition. Psychonomic Bulletin \& Review, 9(4), 625-636. http://dx.doi.org/10.3758/BF03196322.

Winkielman, P., Schwarz, N., Fazendeiro, T. A., \& Reber, R. (2003). The hedonic marking of processing fluency: Implications for evaluative judgment. In J. Musch, \& K. C. Klauer (Eds.), The psychology of evaluation: Affective processes in cognition and emotion (pp. 189-217). Mahwah, NJ: Lawrence Erlbaum.

Wu, L., \& Barsalou, L. W. (2009). Perceptual simulation in conceptual combination: Evidence from property generation. Acta Psychologica, 132(2), 173-189. http://dx.doi.org/10.1016/j.actpsy.2009.02.002.

Please cite this article as: Eelen, J., et al., Situated embodied cognition: Monitoring orientation cues affects product evaluation and choice, Journal of Consumer Psychology (2013), http://dx.doi.org/10.1016/j.jcps.2013.04.004 